\title{
Additive manufacturing of metal-bonded grinding tools
}

\section{Berend Denkena ${ }^{1}$ - Alexander Krödel ${ }^{1} \cdot$ Jan Harmes ${ }^{1} \cdot$ Fabian Kempf $^{1} \cdot$ Tjorben Griemsmann $^{2} \cdot$ Christian Hoff $^{2}$. Jörg Hermsdorf ${ }^{2} \cdot$ Stefan Kaierle $^{2}$}

Received: 8 January 2020 / Accepted: 9 March 2020 / Published online: 20 March 2020

(C) The Author(s) 2020

\begin{abstract}
Grinding tools with superabrasive grains can be manufactured from different bond materials. In several industrial applications, metallic bond systems are used. In general, these show good grain retention and offer a high thermal conductivity, when compared to the other widely used bond types such as vitrified and resin bonds. One drawback of the metallic bond is the lack of pores in the grinding layer. This is caused by the manufacturing processes that are typically used, like brazing or hot pressing. These generally produce very dense layers. The high density and low porosity lead to comparatively little space for the transport of lubricant, coolant, and chips. One approach to eliminate this disadvantage is to introduce cavities into the grinding layer, using the laser powder bed fusion technique (LPBF). In order to evaluate the general suitability of LPBF in combination with the bond material and diamond grains, grinding layer samples with a nickel-titanium bond were produced. The abrasive behavior of these samples was tested in scratch tests on cemented carbide to verify the applicability as grinding tools. While the diamond grains in the powder mixture are not part of the fusion process, they also did not interfere with the manufacturing process, and the scratch tests showed promising abrasive capabilities. The grinding layer itself withstood the process forces, and no grain breakout could be observed. This indicates that the grain retention forces are high enough for the grinding process and that NiTi has a high potential as a bonding material for the manufacturing of grinding tools via LPBF.
\end{abstract}

Keywords Selective laser melting $\cdot$ Laser powder bed fusion $\cdot$ Additive manufacturing $\cdot 3 \mathrm{D}$ printing $\cdot$ Grinding tools $\cdot$ Nitinol

\section{Introduction}

Superabrasive grains offer a high wear resistance compared to corundum and silicon carbide, which allows the manufacturing of high-performance grinding tools. Different bond systems can be used to build these tools, such as ceramic (vitrified bond), polymer (resin bond), and metal (electroplated or sintered), as well as a couple of types of newer hybrid bonds. Each bond has its unique spectrum of properties, which defines the suitability for the respective grinding application. Metal bonds, in general, retain the diamond grains better than, for example, vitrified or resin bonds and also exhibit a higher

Fabian Kempf

kempf@ifw.uni-hannover.de

1 Institute of Production Engineering and Machine Tools (IFW), Leibniz Universität Hannover, An der Universität 2, 30823 Garbsen, Germany

2 Laser Zentrum Hannover e.V. (LZH), Hollerithallee 8, 30419 Hannover, Germany thermal conductivity than these bond types. However, they have low porosity and therefore less room for transporting chips and lubricant [1]. The latter can in part be compensated by the overall good thermal conductivity of the entire tool. For bronze-bonded grinding wheels, it has been shown that the mechanical properties directly relate to the grinding behavior in the form of different grain protrusions after sharpening [2] and the wear rate during grinding [3]. These mechanical properties, for example, change when the grain concentration is increased. This is mainly caused by the reduction of the bond content. For bronze bonds, this reduction leads to a decrease in critical bond stress. The relation between grain content and critical bond stress can be described by a linear trend $[4,5]$. This effect can also be transferred to porosity, causing porous metal-bonded tools to be more demanding during the manufacturing process, because of the decreased loadbearing capability of the grinding layer in comparison to dense tools. In recent years, porous metal-bonded grinding wheels were developed to further improve the performance of metalbonded grinding tools [6]. These tools combine the characteristic properties of metallic bonds with the ones from vitrifiedbonded grinding tools in a way that improves the grinding 
behavior: The excellent thermal properties and low tendency to wear of the metallic bond are improved by the high porosity of the vitrified bond, improving chip transport from, and coolant/lubricant into the contact area $[6,7]$.

One approach to generate pores in metal bonds is the manufacturing of the grinding layer via additive manufacturing techniques. Laser powder bed fusion (LPBF) is a wellknown additive manufacturing (AM) technique, which enables the construction of metal parts with functional integrations, small rate productions, and topology optimized products for weight reduction with increased stiffness. Another major advantage is the production of individual products without a need for special tools and long production times [8]. LPBF is a technique for a large range of metal powders. The fabrication of stainless steel, aluminium, titanium, cobalt chrome, and nickel-based alloys is already state of the art in several industries like aircraft, space, molding tools, and medicine [9]. But there is a high effort in research to develop processes for several other materials like magnesium alloys or NiTi $[10$, 11]. In the case of grinding tools, this technique could enable the construction of fully functional prototypes and tools for special applications with small lot sizes. Another future application could be the integration of special engineered cavities, which support the grinding process.

$\mathrm{Ni}-\mathrm{Ti}$ alloys are suitable as a new type of bond for highperformance grinding wheels due to their chemical grain bond. Because of its high ductility and the affinity for work hardening, NiTi is difficult to handle in milling processes [12]. For this reason, laser techniques are predestinated for processing NiTi. For the manufacturing of 3D structures, LPBF can be used. Because of the interesting material characteristics, like shape memory effect or superelasticity, several research groups are conducting investigations on pure pre-alloyed NiTi in additive manufacturing [13-16]. There are also reports about trials with elemental nickel and titanium powders [17]. Recently, it was shown that the manufacturing of grinding layers using AlSil0Mg as a bond and diamonds as abrasive is possible [18]. In these investigations, the formation of the salt-like carbide aluminium carbide $\left(\mathrm{Al}_{4} \mathrm{C}_{3}\right)$ between the diamond and the bond was postulated. The application of these tools showed good grain retention, which allowed the removal of material from a workpiece of quench-hardened $\mathrm{Cr} 4 \mathrm{~W} 2 \mathrm{MoV}$ cold die steel [19]. Spierings et al. used a $\mathrm{Cu}-$ $\mathrm{Sn}-\mathrm{Ti}-\mathrm{Zr}$ alloy and nickel-coated diamonds as a composite material in the LPBF process. The results are showing some porosity and cracks. Scratch tests are not carried out. Nevertheless, a formation of TiC is assumed [20]. NiTi as a bond has the potential to create superelastic grinding tools with enhanced wear resistance. Furthermore, the diamonds may develop a chemical bonding to the matrix material in the form of titanium carbide. Based on the state of the art, there is no process for the LPBF manufacturing of NiTi diamond composites for grinding tools. In this paper, process development in two steps is given. In the first step, the feasibility of NiTi diamond composites manufactured by LBPF is proven through single tracks, and in the second one, the LPBF process is adapted for cuboid test specimens. Afterwards, the usability is proven in scratch tests.

For most metal bonds, the grain is primarily retained by the positive locking of the grain by the metallic matrix. Several elements can be used to produce additional grain retention via chemical bondings: TiC and chromium [21-23] or boron [24] are often used to improve the interface $[25,26]$. Besides the improvement in adhesion of the diamond grain, a carbide interface can also improve the conductivity of heat between the diamond and the metal matrix [27, 28]. However, the addition of such similar elements can also have a negative effect on the diamond due to the formation of graphite. It has been shown that cobalt, iron, and nickel form graphite during the sintering process, whereas chromium and copper do not show this behavior [21].

\section{Experimental procedure and methodology}

\subsection{Analytical methods}

X-ray diffraction (XRD) was used to characterize the phases present in the manufactured samples. The measurements were performed by a two-circle diffractometer system XRD 3003 TT in a $\Theta / \Theta$ setup. The obtained diffractograms were analyzed with the software powder cell [29]. Furthermore, theoretical diffraction patterns were simulated from crystallographic data.

Scanning electron microscope (SEM) micrographs were obtained via a Zeiss EVO 60 VP and an FEI Quanta 400 FEG, respectively. For the identification of diamond inside the bond material, a backscattered electron (BSE) detector was used. The elemental composition of X-ray diffraction measurements was done with a Seifert XRD 3003TT diffractometer, and a copper and a cobalt target were used to collect the data. The theoretical diffraction patterns used to evaluate the X-ray data, and the evaluation itself was done by the software PowderCell 2.3 [29].

\subsection{LPBF process}

In this paper, two different powder mixtures are tested as a matrix material for the diamonds (Van Mopes D46 FMD60). The first mixture is conventionally milled nickel and titanium as it is normally used for sintered grinding tools. The second one is a pre-alloyed gas atomized NiTi powder. The compositions are shown in Table 1.

The LPBF investigations in this paper are carried out using a laboratory machine for small amounts of powder. The schematic construction is shown in Fig. 1. A fiber laser (SPI Lasers) with a maximum laser power $\mathrm{P}_{\mathrm{L}}$ of $50 \mathrm{~W}$ in continuous wave mode and a wavelength of $1070 \mathrm{~nm}$ is used for the examinations. The focus 
Table 1 Composition of the investigated mixtures

\begin{tabular}{lll}
\hline Powder & Matrix material & Percentage of diamonds (D46) \\
\hline$\# 1$ & Nickel $(50.3 \mathrm{wt} \%)+$ titanium $(49.7 \mathrm{wt} \%)$ & $25 \mathrm{v} \%$ \\
$\# 2$ & NiTi pre-alloyed $(\approx 55.5 \mathrm{wt} \% \mathrm{Ni} 44.5 \mathrm{wt} \% \mathrm{Ti})$ & $28 \mathrm{v} \%$ \\
\hline
\end{tabular}

size is $19 \mu \mathrm{m}$ in the diameter, and the laser beam is guided by a galvanometric scanner (Fa. Scanlab). Argon is used as a process gas to create an inert atmosphere, and resulting fumes during the process are exhausted by a TEKA filter system. The maximum size of the build platform has a diameter of $49 \mathrm{~mm}$.

To get a first insight of the process behavior of NiTi with diamonds dispersed in the powder, line scan trials together with T-structures are carried out. The t-structures are two orthogonal line scans with a connection. They are used to get a first impression on more complex geometries. A laser power of $\mathrm{P}_{\mathrm{L}}=25 \mathrm{~W}$ and a scanning speed of $\mathrm{v}=110 \mathrm{~mm} / \mathrm{s}$ are used based on previous work [11] for pure NiTi. The structures are built to a height of $1.5 \mathrm{~mm}$ directly on a NiTi sheet as a substrate.

For scratch tests, cubic volume bodies are required. To evaluate suitable process parameters, a short parameter study is carried out for the pure NiTi powder \#2 without diamonds. Cubes with an edge length of $2.5 \mathrm{~mm}$ are built on block support structures. The scanning speed is kept constant at $110 \mathrm{~mm} / \mathrm{s}$. The parameters' laser power $\mathrm{P}_{\mathrm{L}}$ and hatch distance $\mathrm{d}$ are varied as follows:

- $\mathrm{P}_{\mathrm{L}}: 20 \mathrm{~W}$ to $50 \mathrm{~W}$ in $5 \mathrm{~W}$ steps

- $\mathrm{d}: 20 \mu \mathrm{m}$ to $60 \mu \mathrm{m}$ in $10 \mu \mathrm{m}$ steps

For each cube, one factor is changed at a time. The specimens are examined through cross sections. Images are taken with a light microscope (Fa. Leitz) and the software AxioVision (Fa. Carl Zeiss). The relative density is determined by a python script using the computer vision package OpenCV for automated detection of pores in the light microscope images. The sum of the pore area is set in relation to the overall area of the cross section to determine the relative density.

Based on the results described in Sect. 3.1, the test specimens for scratch tests are built with powder \#2 and diamonds. The dimensions of the cuboid specimens are $4.95 \mathrm{~mm} \times 4.95 \mathrm{~mm} \times$ $3 \mathrm{~mm}$. All samples are built with block supports on a NiTi sheet as a substrate. All LPBF investigations used a slice height of $50 \mu \mathrm{m}$.

SEM images are made to investigate the shape and distribution of the diamonds. An EDX mapping is performed to illustrate the distribution of the elements within the metallic matrix, and polish grindings are used to evaluate the inner structure of the samples and the diamond dispersion in the whole specimen.

\subsection{Grinding process}

To check whether the manufactured segments are sufficiently resilient and can be used as an abrasive layer on grinding wheels, scratch tests on tungsten carbides are performed. These tests were carried out on a flat grinding machine FS 480 KT CNC made by Geibel and Hotz. The printed segments are bonded to a metal pin with Crystalbond ${ }^{\mathrm{TM}}$. These pins are attached to a scratch disc. Like conventional metal-bonded multilayered grinding tools, these segments have to undergo a dressing step, which for metallic-bonded tools is usually divided into a profiling and a sharpening process. For the segments used in these investigations, profiling means shaping the profile to being flat, when looking towards the cutting direction, and generating the radius of the tool path, when
Fig. 1 Construction of the used laboratory machine

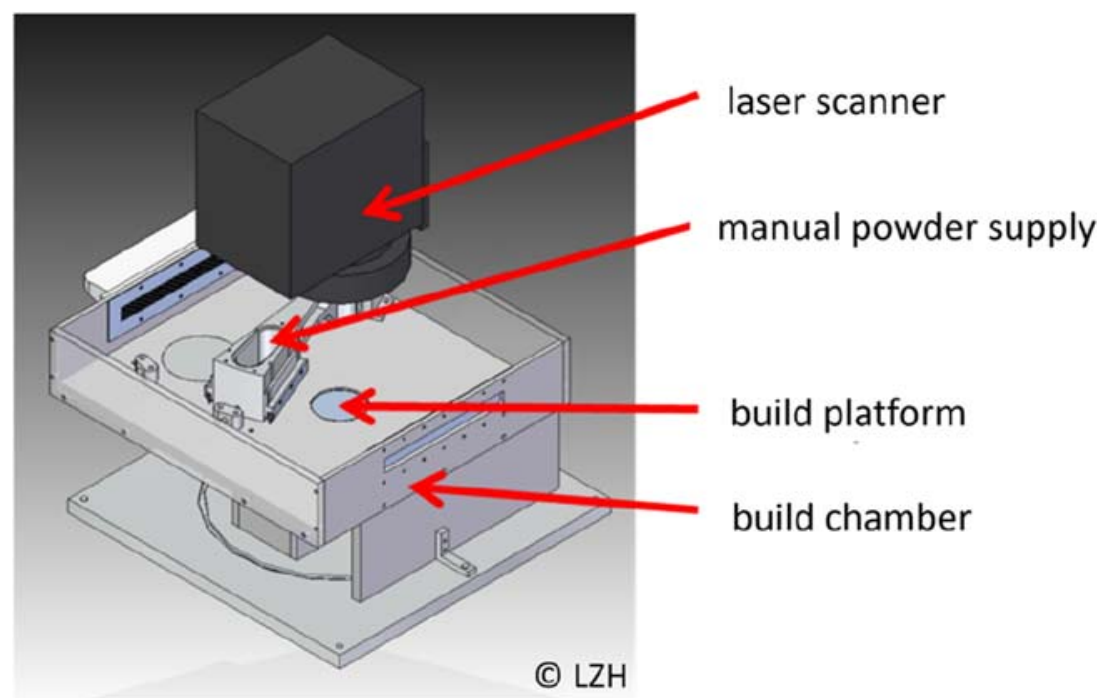


Fig. 2 Experimental setup for scratch tests
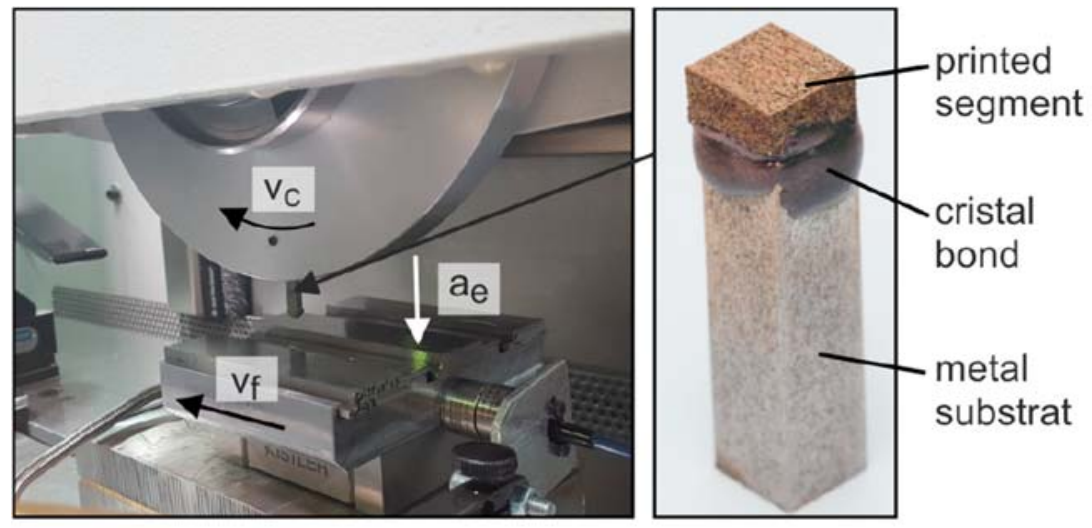

$\begin{array}{ll}\text { Process: } & \text { Material: } \\ \text { scratch test } & \text { cemented carbide } \\ \text { Tool: } & \text { KXF }\end{array}$

D46 NiTi
Process parameters:
$\mathrm{v}_{\mathrm{C}} \quad=20 \mathrm{~m} / \mathrm{s}$
$\mathrm{v}_{\mathrm{f}}=200 \mathrm{~mm} / \mathrm{min}$
$a_{e}=10 \mu \mathrm{m}$
Har/94915 @IFW

looking along the axis of the machine spindle. The sharpening process then improves the amount of grain protrusion. To do so, the tool is used to machine a piece of vitrified corundum. This mainly removes bond material around the diamond grains. For larger grinding tools, these two processes employ different tools. However, due to the little amount of material that has to be removed in this case, both processes are done in one step using vitrified white corundum. Afterwards, a polished and evenly leveled tungsten carbide specimen (KXF, 10\% Co, $0.7 \mu \mathrm{m}, 1610 \mathrm{HV} 30$ ) is machined for the scratch tests (Fig. 2).

The sharpened segment surfaces and generated scratch paths are measured with a laser profilometer from the company NanoFocus. The analysis of the measured data is done with the software MountainsMap from the company Digital Surf.
Fig. 3 Scanning electron microscope images of T-structures
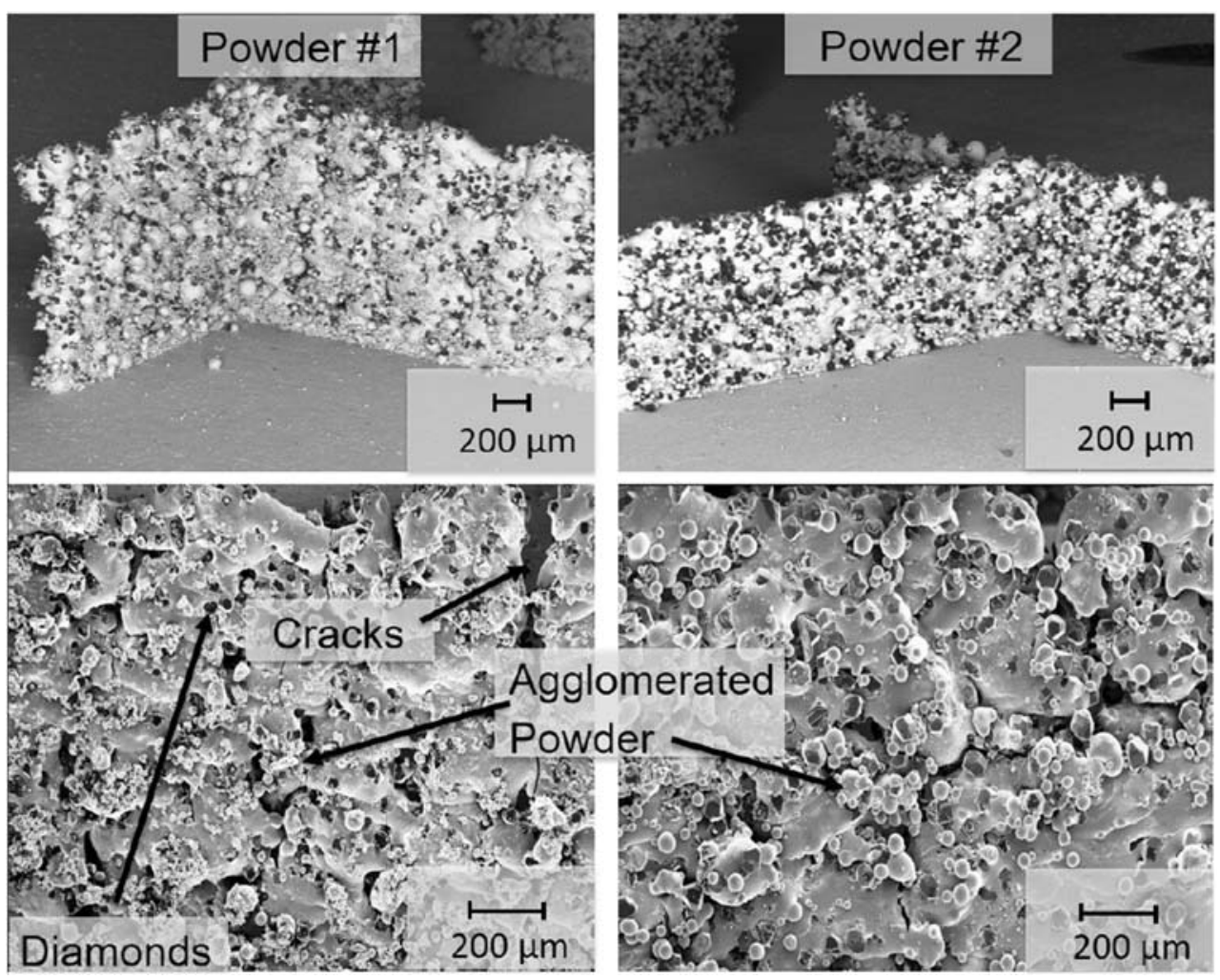
Fig. 4 Distribution of elements in the line can trials of powder \#1
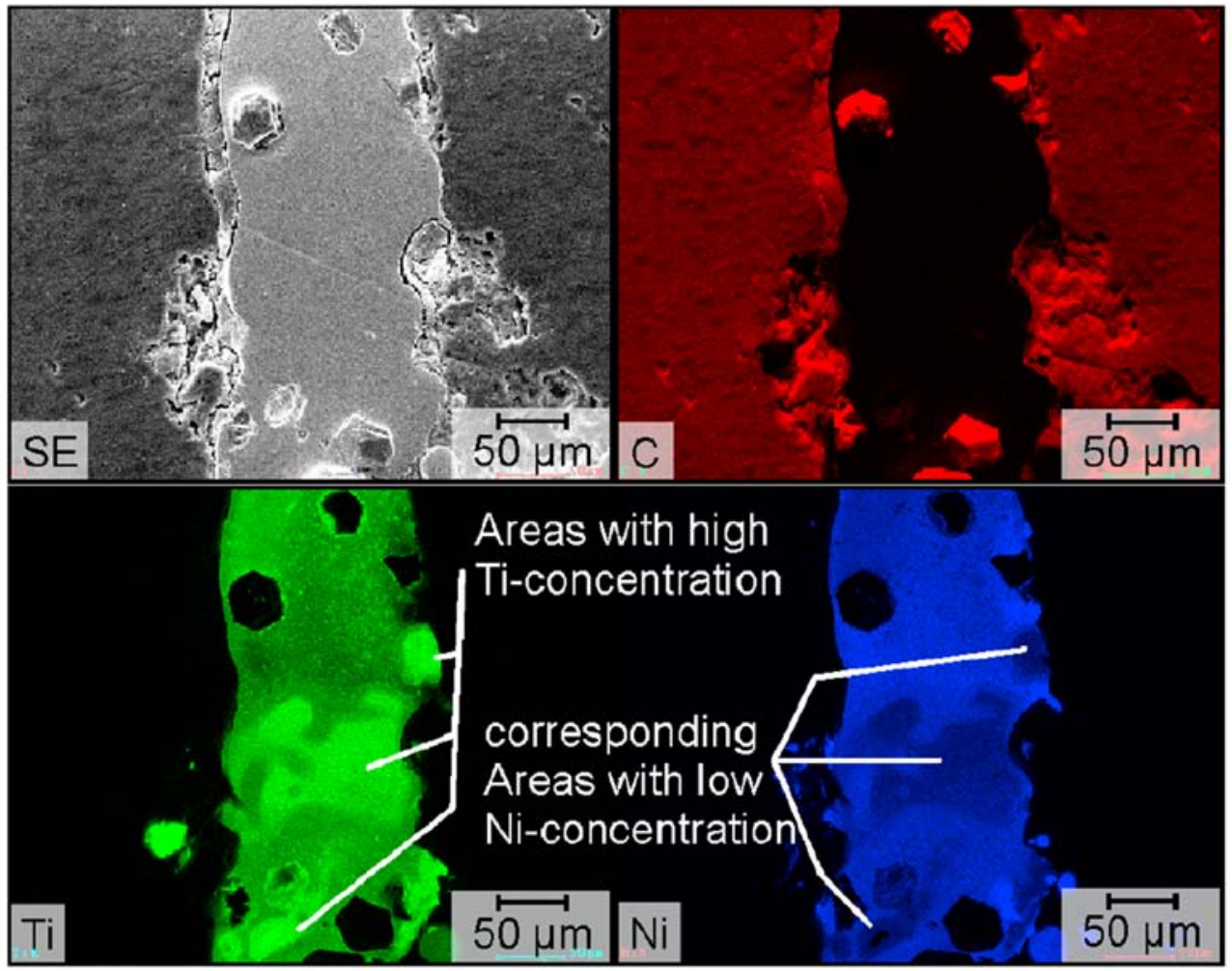

$\mathrm{Km} / 94746$ 이FW

\section{Results and discussion}

\subsection{LPBF process for line scan and T-structures}
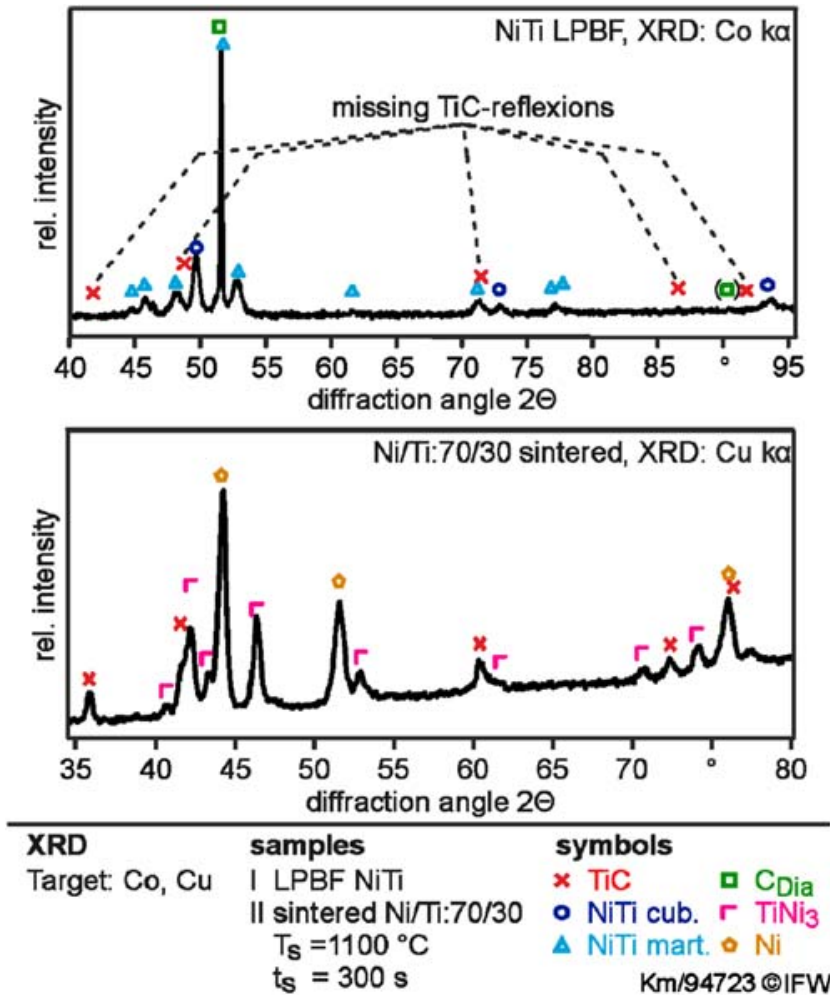

Fig. 5 XRD patterns of LPBF manufactured and sintered samples

All line can and T-structure trials are successfully built as they did not break during the building process. The results are shown in Fig. 3. The samples built with the spherical powder \#2 show smoother surfaces and a more homogeneous distribution of the diamonds than the samples from powder \#1. Furthermore, bigger cracks are found in the lines built from powder \#1. One explanation could be shown in Fig. 4, which shows the distribution of the elements in the tracks built from powder \#1. Titanium and nickel are not distributed homogeneously. Areas with higher accumulations of titanium could lead to crack formation due to brittleness. Since powder \#2 is pre-alloyed, the element distribution is more homogeneous after the LPBF process. As a result, further investigations with test specimens for scratch tests are carried out with powder\#2.

Table 2 Processed parameter sets from powder 2 with diamonds

\begin{tabular}{llcl}
\hline Parameter set & $\mathrm{P}_{\mathrm{L}}$ in $\mathrm{W}$ & $\mathrm{V}$ in $\mathrm{mm} / \mathrm{s}$ & $\mathrm{E}_{1}$ in $\mathrm{J} / \mathrm{mm}$ \\
\hline 1 & 50 & 110 & 0.45 \\
2 & 25 & 55 & 0.45 \\
3 & 30 & 66 & 0.45 \\
4 & 25 & 110 & 0.23 \\
\hline
\end{tabular}


Fig. 6 Photography of LPBF manufactured test samples with dispersed diamonds. Numeration as in Table 2

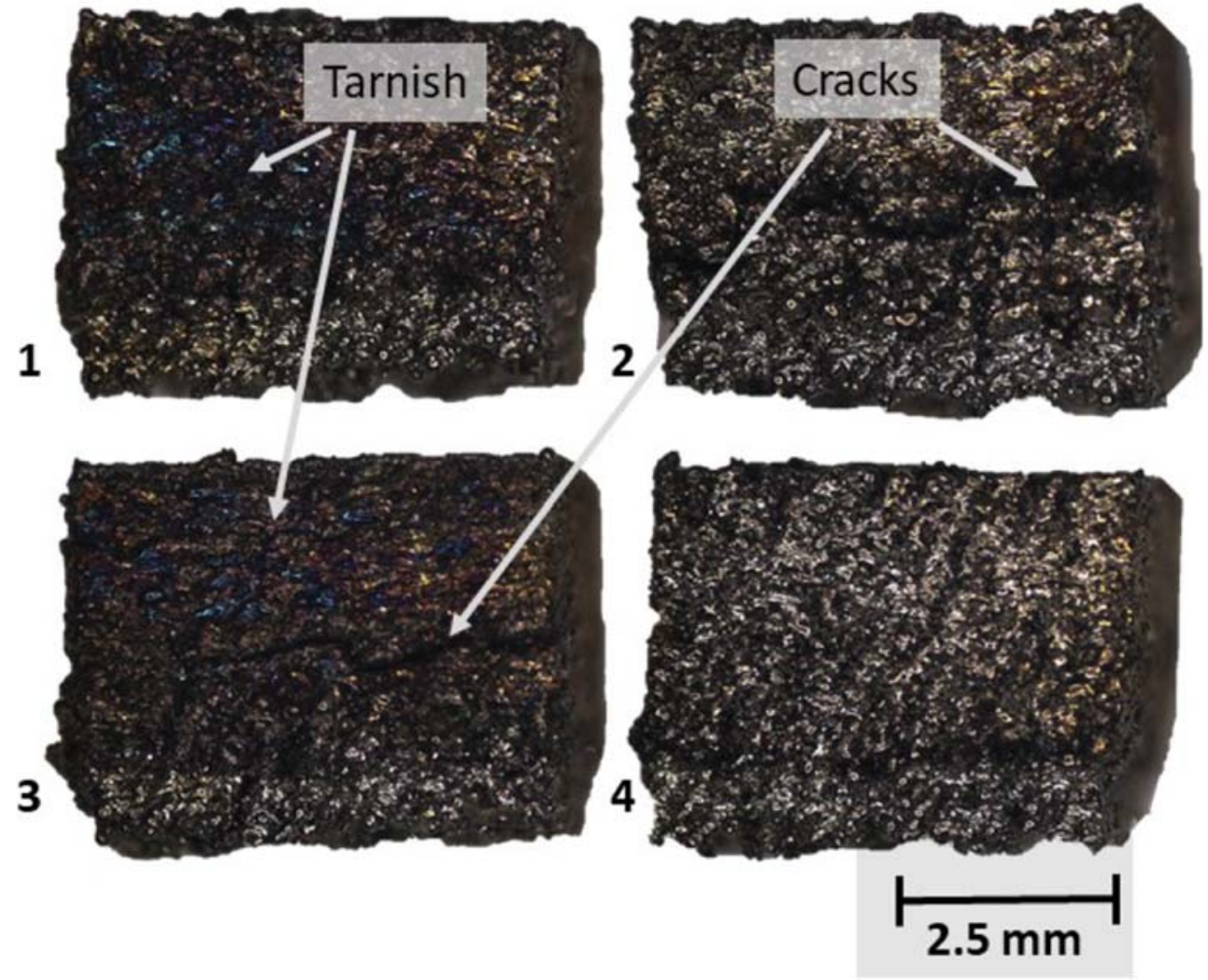

The characterization via XRD confirms the presence of NiTi within the bond. The diffractogram (Fig. 5, top) shows the reflections of both the cubic NiTi phase and the martensitic NiTi phase. It further shows only the $\{111\}$ reflection of the diamond. This is due to the small area that is analyzed (approx. $2 \times 2 \mathrm{~mm}^{2}$ ). This causes a limited number of diamond grains to be inside

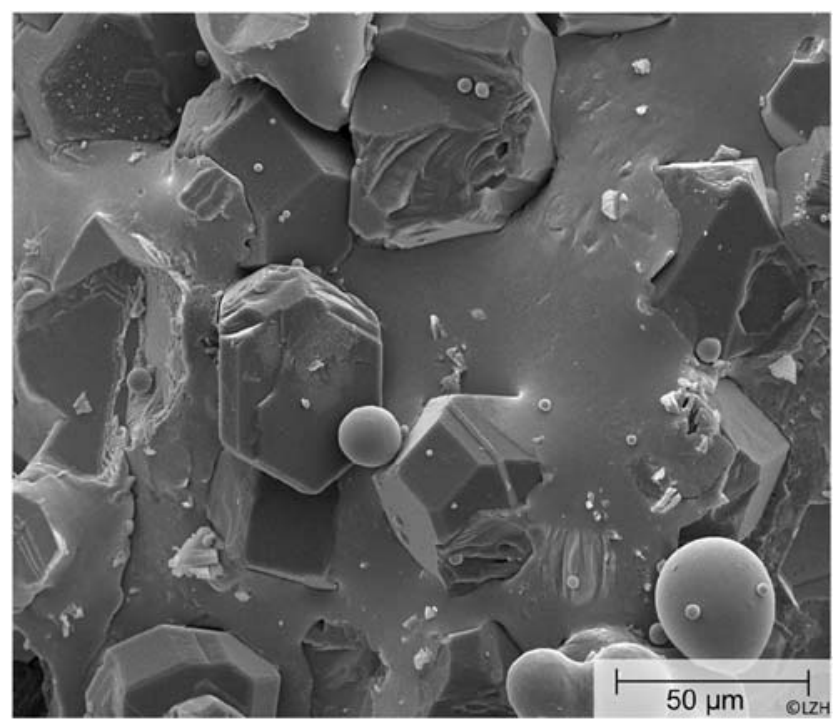

Fig. 7 SEM image (side view) from parameter set 1 the X-ray spot. Because these diamonds are monocrystalline, the absolute number of differently oriented lattice planes that contribute to the signal is low. This leads to a very low number of individual reflections, causing a low probability to hit the comparative small detector area. This, in turn, explains why the other reflections in the measuring range ( $\{220\}$ and $\{311\})$ cannot be observed. Furthermore, the metallic bond prevents deeper penetration of the material, shielding diamonds below the surface and further reducing the number of investigated diamonds. Besides these signals, there are no indications that other phases of the binary system $\mathrm{Ni} / \mathrm{Ti}$ are present $\left(\mathrm{Ni}, \alpha / \beta-\mathrm{Ti}, \mathrm{Ti}_{2} \mathrm{Ni}, \mathrm{TiNi}_{3}\right)$.

In principle, the $\mathrm{Ni}-\mathrm{Ti}$ system can form $\mathrm{TiC}$ in varying degrees. Sintering samples of a mixture of $\mathrm{Ni}$ and $\mathrm{Ti}$ powder and diamond lead to the formation of TiC (Fig. 5, bottom). Due to the combination of the small measuring spot and the low sensitivity of the XRD method towards thin layers, the use of harsher sintering conditions ( $\mathrm{T}>$ $1000{ }^{\circ} \mathrm{C}$ ) showed distinct $\mathrm{TiC}$ reflections. This shows that the formation of titanium carbide takes place. The diffraction pattern of the LPBF sample does not show significant signals at the characteristic diffraction angles. However, fracturing tests of other sintered samples indicate generally good grain retention in this kind of bond. This can be illustrated in a comparison with a commonly used bronze bond $(\mathrm{Cu} / \mathrm{Sn}, 80: 20)$. 


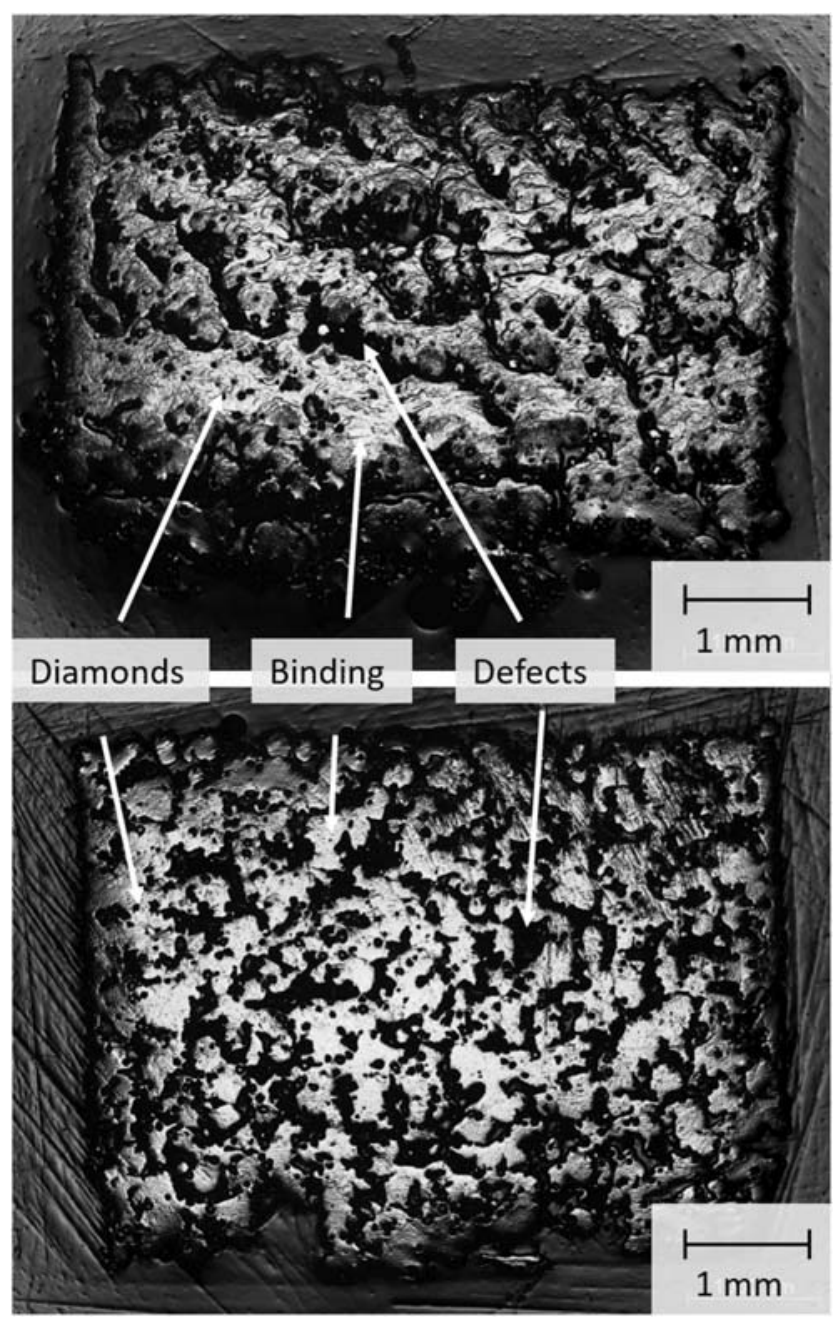

Fig. 8 Light microscope images of cross sections of samples built with the parameter sets 1 (top) and 4 (bottom)

\subsection{LPBF process for cube samples}

The parameter study for NiTi cubes without diamonds reveals the highest relative density with $99.09 \%$ at the following parameter combination:

- $\mathrm{P}_{\mathrm{L}}=50 \mathrm{~W}$

- $\mathrm{v}=110 \mathrm{~mm} / \mathrm{s}$

- $\mathrm{d}=50 \mu \mathrm{m}$

This parameter combination is used as a basis for NiTi cuboids with diamonds dispersed. It is assumed that diamonds influence the laser process. For this reason, additional samples with adapted parameters are built. To investigate the influence of longer laser irradiation on the diamonds, slower scanning speeds with the same energy density $E_{1}$ are used. $E_{1}$ is calculated by Eq. 1 In this context, parameters with $50 \%$ of the energy density are built as well (Table 2). The results of the grinding specimens are shown in Fig. 6 . The specimens built with parameter sets 1-3 made a crackling sound during the process, and the cubes are showing tarnish
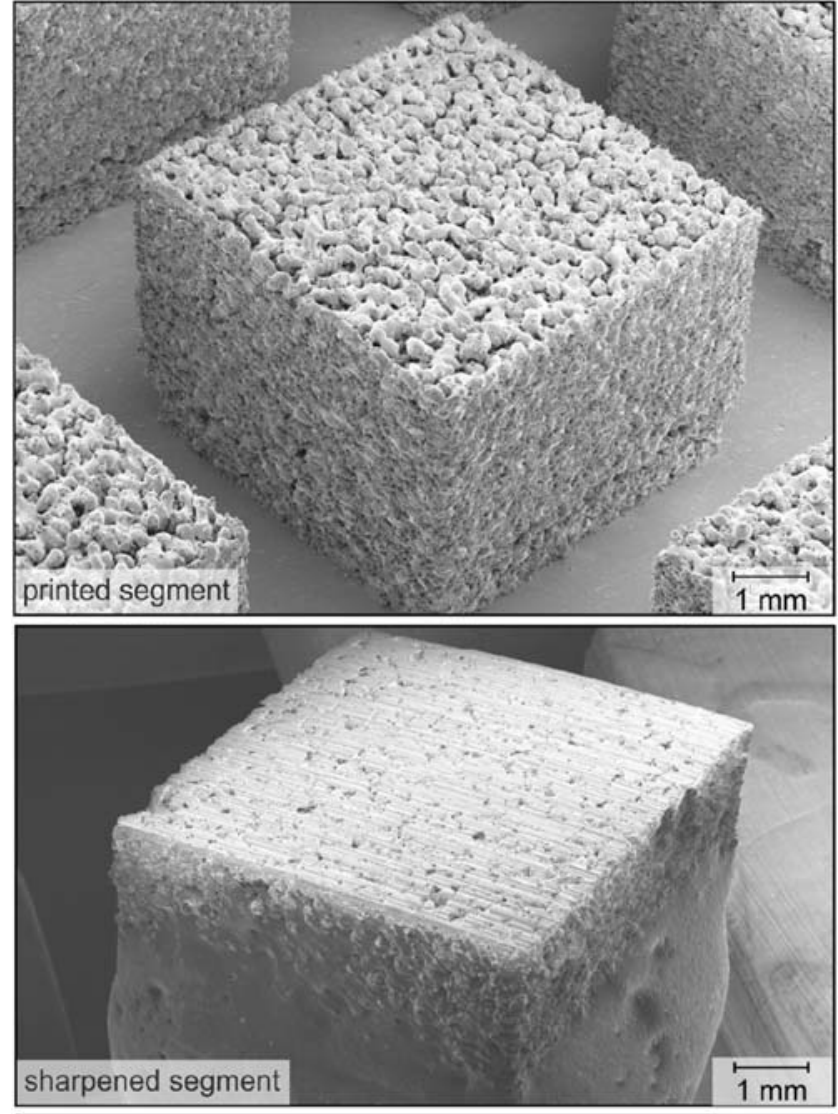

\begin{tabular}{|c|c|c|}
\hline Process: & Material: & Process parameters: \\
\hline & white corundum & $v_{c}=10 \mathrm{~m} / \mathrm{sec}$ \\
\hline Tool: & & $=600 \mathrm{~mm} / \mathrm{min}$ \\
\hline D46 NiTi & & $=15 \mu \mathrm{m}$ \\
\hline
\end{tabular}

Fig. 9 SEM of segments after printing and sharpening

and cracks at the edges. Parameter set 4 leads to only slight crackling and no tarnish.

$E_{l}=\frac{\mathrm{P}_{L}}{v}$

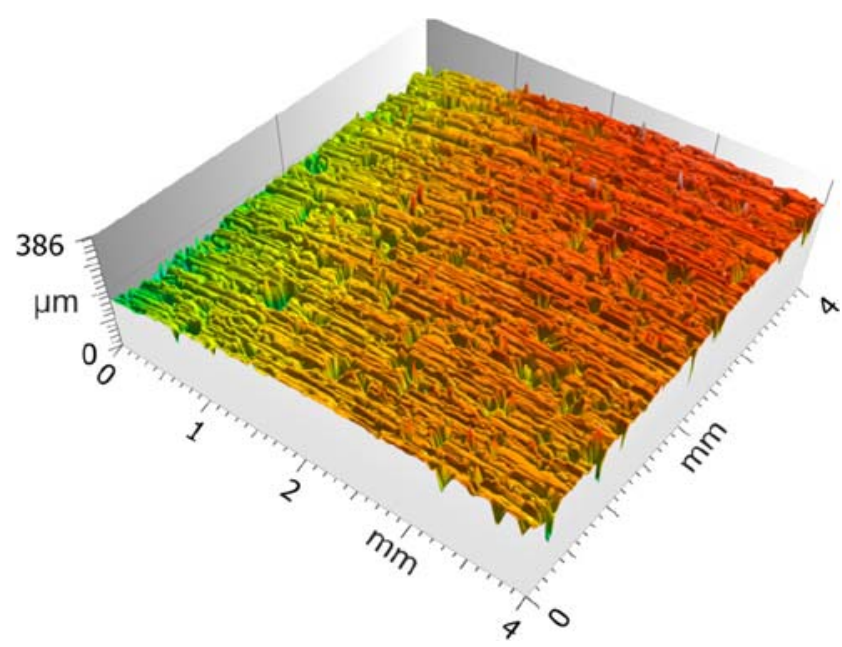

Fig. 10 3D scan of the sharpened grinding layer 


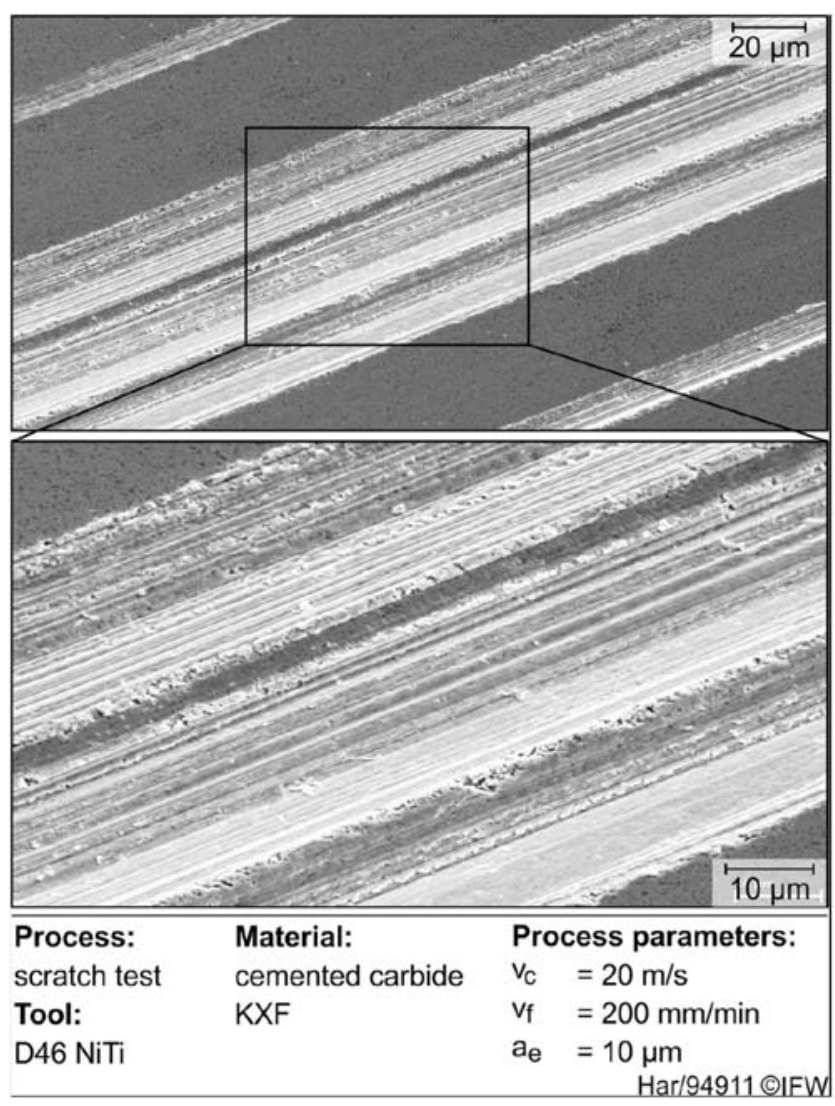

Fig. 11 SEM picture of scratch paths

To evaluate if the crackling sound during the process is a sign of destroyed diamonds, SEM images are made from the parameter set 1. As shown in Fig. 7, no visible damages of the diamonds on the surface can be found. The microscope images of polished cross sections in Fig. 8 show fewer diamonds than expected from the ratio of diamonds to NiTi powder and the surface in Fig. 7. This could explain the abovementioned crackling during the LPBF process. The diamonds on the surface are only partially hit by the laser beam and therefore in a better condition. The diamonds in the specimen volume may be burned or pushed away from the laser material interaction. Because of the cracks which lower the mechanic strength of
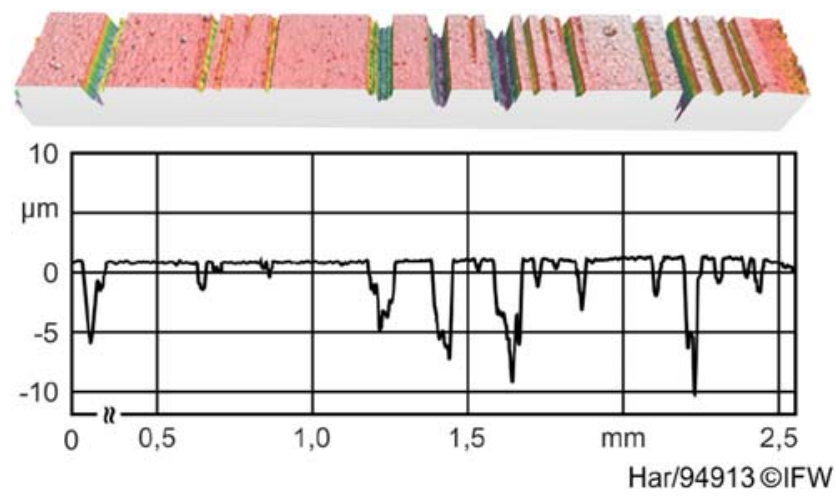

Fig. 12 Laser scan of scratch paths the specimens and the less homogeneous structure in the cross sections in Fig. 8, parameter sets 1-3 are discarded, and parameter 4 is chosen for the scratch tests.

\subsection{Dressing}

To transfer the radius of the tool path to the surface of the attached segments and to generate a sharp state with sufficient grain protrusion, the segments are used to machine white corundum. The tests were performed with a cutting speed of $\mathrm{v}_{\mathrm{c}}=10 \mathrm{~m} / \mathrm{s}$, a feed rate of $\mathrm{v}_{\mathrm{f}}=600 \mathrm{~mm} / \mathrm{min}$, and an in feed of $\mathrm{a}_{\mathrm{e}}=15 \mu \mathrm{m}$ (Fig. 9).

After the dressing process, the printed segments were scanned with a laser profilometer (Fig. 10). The Abbott curve was then used to determine the grain protrusion achieved. The average grain protrusion corresponds to the $\mathrm{s}_{\mathrm{pk}}$ value of the Abbot curve and is $8.27 \mu \mathrm{m}$, which is high enough for the performed scratch tests.

\subsection{Scratch tests}

The tests were performed with a cutting speed of $v_{\mathrm{c}}=20 \mathrm{~m} / \mathrm{s}$, a feed rate of $\mathrm{v}_{\mathrm{f}}=200 \mathrm{~mm} / \mathrm{min}$, and an in feed of $a_{\mathrm{e}}=10 \mu \mathrm{m}$. The material removal shows brittle ruptures on the flanks of the scratch marks, which is typical for the machining of tungsten carbides (Fig. 11).

The scratch paths remain unchanged over the entire workpiece length. This means that the diamonds are held firmly in the bond and no breakage or indents occur. The laser scan of the scratch paths shows depths of up to $10 \mu \mathrm{m}$ (Fig. 12). This corresponds to the grain protrusion and the used cutting depth. Based on these results, the LPBF process can be classified as suitable for the production of abrasive tools used to grind tungsten carbides. The grain retention forces are high enough to prevent the diamonds from breaking out. Based on these investigations, further printed grinding layer geometries can be investigated.

\section{Conclusion and outlook}

Based on the experimental investigations performed, the following conclusions can be drawn:

- Additive manufactured NiTi diamond composites are suitable for the utilization as grinding tools.

- Pre-alloyed NiTi offers a higher potential than a mixture of nickel and titanium powder, because of the distribution of the elements.

- The presence of diamonds leads to an increased affinity for cracks and overheating.

- LPBF process parameters for pure metals are not completely transferable to metal diamond composites. The necessary energy density is lower than for the manufacturing of pure metal components. 
- Diamonds are held firmly into the bond during scratch tests on tungsten carbide.

Funding Information Open Access funding provided by Projekt DEAL.

Open Access This article is licensed under a Creative Commons Attribution 4.0 International License, which permits use, sharing, adaptation, distribution and reproduction in any medium or format, as long as you give appropriate credit to the original author(s) and the source, provide a link to the Creative Commons licence, and indicate if changes were made. The images or other third party material in this article are included in the article's Creative Commons licence, unless indicated otherwise in a credit line to the material. If material is not included in the article's Creative Commons licence and your intended use is not permitted by statutory regulation or exceeds the permitted use, you will need to obtain permission directly from the copyright holder. To view a copy of this licence, visit http://creativecommons.org/licenses/by/4.0/.

\section{References}

1. KlockeF (2009) Manufacturing processes 2 - grinding. Honing, Lapping

2. Denkena B, Grove T, Bremer I et al (2016) Design of bronzebonded grinding wheel properties. CIRP Ann 65(1):333-336. https://doi.org/10.1016/j.cirp.2016.04.096

3. Denkena B, Grove T, Kempf F et al (2019) Model-based manufacturing and application of metal-bonded grinding wheels. CIRP Ann 68(1): 321-324. https://doi.org/10.1016/j.cirp.2019.04.088

4. Kempf F, Bouabid A, Dzierzawa P, Grove T, Denkena B (2017) Methods for the analysis of grinding wheel properties. In: Schmitt R, Schuh G (eds) 7. WGP-Jahreskongress Aachen, 5.-6. Oktober 2017. Apprimus Wissenschaftsverlag, Aachen, pp 87-96

5. Denkena B, Grove T, Göttsching T, Dzierzawa P, Kempf F (2017) Methods of analysis for a deeper understanding of the grinding process. In: Proceedings of the $20^{\text {th }}$ International Symposium on Advances in Abrasive Technology, pp 945-951

6. Denkena B, Grove T, Suntharakumaran V (2018) Porous metal bonds increase the resource efficiency for profile grinding. Procedia CIRP 69: 265-270. https://doi.org/10.1016/j.procir.2017.10.004

7. Denkena B, Köhler J, Krawczyk T (2013) Schleifen von Hartmetall mit porösen metallisch gebundenen Diamantschleifscheiben. Jahrbuch Schleifen, Honen, Läppen und Polieren, Ausgabe 66: 171-178

8. Lippert RB, Lachmayer R (2017) Einleitung. In: Lachmayer R, Lippert RB (eds) Additive Manufacturing Quantifiziert: Visionäre Anwendungen und Stand der Technik. Springer, Berlin Heidelberg, pp 1-6

9. Wessarges Y, Gieseke M, Hagemann R et al (2017) Entwicklungstrends zum Einsatz des selektiven Laserstrahlschmelzens in Industrie und Biomedizintechnik. In: Lachmayer R, Lippert RB (eds) Additive Manufacturing Quantifiziert: Visionäre Anwendungen und Stand der Technik. Springer, Berlin Heidelberg, pp 7-21

10. Gieseke M (2015) Entwicklung des selektiven Laserstrahlschmelzens von Magnesium und Magnesiumlegierungen zur Herstellung von individuellen und bioresorbierbaren Implantaten. Dissertation, Leibniz Universität Hannover; TEWISS - Technik und Wissen GmbH

11. Hagemann R, Overmeyer L, Wolkers WF (2018) Additive Fertigung von Nickel-Titan-Mikroaktoren für Cochlea-Implantate. Dissertation, Leibniz Universität Hannover

12. Weinert K (ed) (2005) Spanende Fertigung: Prozesse, Innovationen, Werkstoffe, 4. Ausg. Vulkan Verl., Essen

13. Andani MT, Shayesteh Moghaddam N, Haberland C, Dean D, Miller MJ, Elahinia M (2014) Metals for bone implants. Part 1. Powder metallurgy and implant rendering. Acta Biomater 10(10): 4058-4070. https://doi.org/10.1016/j.actbio.2014.06.025
14. Bormann T, Schumacher R, Müller B et al (2012) Tailoring selective laser melting process parameters for NiTi implants. J Mater Eng Perform 21(12):2519-2524. https://doi.org/10.1007/s11665-012-0318-9

15. Shishkovsky IV, Yadroitsev IA, Smurov IY (2013) Manufacturing three-dimensional nickel titanium articles using layer-by-layer laser-melting technology. Tech Phys Lett 39(12):1081-1084. https://doi.org/10.1134/S1063785013120250

16. Dadbakhsh S, Speirs M, Kruth J-P et al (2014) Effect of SLM parameters on transformation temperatures of shape memory nickel titanium parts. Adv Eng Mater 16(9):1140-1146. https://doi.org/10. 1002/adem.201300558

17. Zhang B, Chen J, Coddet C (2013) Microstructure and transformation behavior of in-situ shape memory alloys by selective laser melting Ti-Ni mixed powder. J Mater Sci Technol 29(9):863867. https://doi.org/10.1016/j.jmst.2013.05.006

18. Tian C, Li X, Zhang S, Guo G, Ziegler S, Schleifenbaum JH, Wang L, Rong Y (2019) Porous structure design and fabrication of metalbonded diamond grinding wheel based on selective laser melting (SLM). Int J Adv Manuf Technol 100(5-8):1451-1462. https://doi. org/10.1007/s00170-018-2734-y

19. Tian C, Li X, Zhang S et al (2018) Study on design and performance of metal-bonded diamond grinding wheels fabricated by selective laser melting (SLM). Mater Des 156:52-61. https://doi. org/10.1016/j.matdes.2018.06.029

20. Spierings AB, Leinenbach C, Kenel C et al (2015) Processing of metaldiamond-composites using selective laser melting. Rapid Prototyp J 21(2):130-136. https://doi.org/10.1108/RPJ-11-2014-0156

21. Tillmann W, Ferreira M, Steffen A et al (2013) Carbon reactivity of binder metals in diamond-metal composites-characterization by scanning electron microscopy and X-ray diffraction. Diam Relat Mater 38:118-123

22. Tang Y, Wang L, Zhao C (2014) Enhancement of the thermal properties of silver-diamond composites with chromium carbide coating. Appl Phys A Mater Sci Process 115(2):379-385. https://doi. org/10.1007/s00339-014-8254-1

23. Mizuuchi K, Inoue K, Agari Y et al (2015) Effect of chromium addition on the thermal conductivity of $\mathrm{Cu}$ /diamond composites fabricated by SPS. J Jpn Soc Powder Powder Metall 62(7):357364. https://doi.org/10.2497/jjspm.62.357

24. Mizuuchi K, Inoue K, Agari Y et al (2015) Effect of boron addition on the thermal conductivity of $\mathrm{Cu}$ /diamond composites fabricated by SPS. J Jpn Soc Powder Powder Metall 62(1):27-34. https://doi. org/10.2497/jjspm.62.27

25. Khalid F (2004) On the interfacial nanostructure of brazed diamond grits. Scr Mater 50(8):1139-1143. https://doi.org/10.1016/j. scriptamat.2004.01.024

26. Kamiya O, Tsuji D, Ashihara F et al (2012) Diamond and metal bonding by active solder for micro - cutting wire. Int J Mod Phys B 20(25n27):3932-3937. https://doi.org/10.1142/S0217979206040611

27. Schatt W, Kieback B, Wieters K-P (eds) (2007) Pulvermetallurgie: Technologien und Werkstoffe, 2., bearbeitete und erweiterte Auflage. VDI-Buch. Springer-Verlag Berlin Heidelberg, Berlin, Heidelberg

28. Mańkowski P, Dominiak A, Domański R et al (2014) Thermal Conductivity Enhancement of Copper-Diamond Composites by Sintering with Chromium Additive. J Therm Anal Calorim 116(2):881-885. https://doi.org/10.1007/s10973-013-3604-3

29. Kraus W, Nolze G (1996) Powder Cell - a Pro-gram for the Representation and Manipulation of Crystal Structures and Calculation of the Result-ing X-ray Powder Patterns. J Appl Crystallogr 29(3):301-303

Publisher's note Springer Nature remains neutral with regard to jurisdictional claims in published maps and institutional affiliations. 